\section{US sanctions put research at risk}

Scientific collaboration during the cold war was one of the few links between the United States and the Soviet Union. It is sad and ironic that today's partnerships may now bear the brunt of US sanctions as a result of the situation in Ukraine (see Nature 508, 162; 2014).

Earlier this month, the FBI warned universities in Boston, Massachusetts, about venturecapital partnerships with Russia (see go.nature.com/oyxpth). The US government is also severing scientific exchange by NASA and the Department of Energy with scientists in Russia. These moves are causing widespread consternation in the Russian research community.

Former Soviet and now Russian scientists have traditionally subscribed to democratic and pro-Western agendas (the nuclear physicist Andrei Sakharov is one famous example). Moreover, researchers, engineers and entrepreneurs of Russian origin have contributed significantly to the US enterprise. Indeed, after the collapse of the Soviet Union, the US government issued fast-track green cards to Russian scientists to retain their expertise.

By contrast, the new US policies are likely to be counterproductive. The presumption that Russian scientists are potential spies will force them to return to or stay in Russia, where research is in disarray because of sweeping reforms. Researchers whose projects are derailed are likely to blame the United States rather than Russia - a situation that could further damage relations.

There are signs that Russian scientists with foreign collaborators may come under more state control. It seems that both US and Russian bureaucrats lack understanding of the importance of international scientific collaborations and the way modern science works. Konstantin Severinov Rutgers
University, New Jersey, USA; and Skolkovo Institute of Science and Technology, Russia.

severik@waksman.rutgers.edu

\section{Ecology must seek universal principles}

I disagree with your advice to stop searching for universal principles in ecology (Nature 507, 139-140; 2014). It is fortunate that Darwin held no such view. And in this era of big data, big theories are still needed - even in ecology.

The "caveats and exceptions" in existing theory, which you imply scuttle efforts to build better theory, are the very foundation for improvement. This is how science progresses; ecology is no exception.

You recommend that "ecologists should embrace the non-predictive side of their science", but prediction is part of what distinguishes science from other worthwhile endeavours; it enables us to strengthen and refine our understanding.

Using the wolves in

Yellowstone National Park as an example to support your view is ironic. Top-down trophic control in multispecies populations is not a theory: it is an oversimplified conceptual model - a good story that is known to apply sometimes. It remains to be seen whether a unified theory of trophic, competitive and facilitative interactions among species can be achieved, but ecologists should not be advised to give up now.

John Harte University of California, Berkeley, USA. jharte@berkeley.edu

\section{Mental health: more than neurobiology}

The decision by the US National Institute of Mental Health (NIMH) to fund only research into the neurobiological roots of mental disorders (Nature 507, 288 ; 2014) presumes that these all result from brain abnormalities. But this is not the case for many people with mental-health issues and we fear that this policy could stall clinical insight into mental illness for years to come.

There is no consistent biological evidence to support the idea that all mental disorders are due to brain dysfunction. Mood and anxiety, for example, are multifactorial and depend on biological, psychological and environmental factors.

The NIMH's assumption of underlying neural mechanisms presupposes that symptoms of specific disorders cluster because they have the same biological cause. However, psychopathological symptoms of disorders such as depression differ dramatically in their causes and genetic context and do not have a common biological background (E. I. Fried et al. Psychol. Med. http://doi.org/ r93; 2013). Symptoms are more likely to cluster because of causal connections - for example, insomnia and its side effects are widespread features of various psychiatric conditions.

Eiko Fried, Francis Tuerlinckx University of Leuven, Belgium. eiko.fried@gmail.com

Denny Borsboom University of Amsterdam, the Netherlands.

\section{Mental health: drug search on risky path}

I fear that the requirement by the US National Institute of Mental Health for investigators to come up with a hypothesis as an initial part of the drug-discovery process (Nature 507, 273 and 288 ; 2014) will not end well.

The discovery of all early and most recent drugs has hinged on testing the effects of small molecules on the phenotype of cells and organisms (M. J. Keiser et al. Biochemistry 49, 10267-10276; 2010). A hypothesis is not needed (D. B. Kell and S. G. Oliver BioEssays 26, 99-105; 2004) and finding a drug's likely targets can be postponed until it is known whether the drug works.
It is now more fashionable to start the drug-discovery process with a hypothesis on how a drug might act on (typically) a single target, then to test how effective it is. But if the hypothesis turns out to be wrong, which is not unusual (D. B. Kell FEBS J. 280, 5957-5980; 2013), money and effort will have been wasted.

Douglas Kell University of Manchester, UK. dbk@manchester.ac.uk

\section{Restore public trust in care.data project}

Public confidence has already been undermined in the National Health Service's care.data programme in England, which will integrate medical records into a database for health-care and research purposes (Nature 507, 7; 2014). We suggest that the UK government's decision to limit release of the data should be the start of a process to develop public trust in large-scale health research, not an end to it.

Care.data first needs to provide more information to the public about how medical records will be used. Openness and clarity are essential. For example, the UK Health and Social Care Information Centre (which manages the data) can currently share pseudonymized data with 'such persons and in such form and manner... as it considers appropriate': these choices should be fully explained to the public.

A proposed amendment to the Health and Social Care Act 2012 might narrow this discretion so that data can be shared only for 'the promotion of health'. But even this is open to wide interpretation.

Formal regulation is only one way to reassure the public. Another is to use online interfaces that allow research participants to access information and to set consent preferences (J. Kaye et al. Eur. J. Hum. Genet., in the press). Colin Mitchell, Linda Briceno Moraia, Jane Kaye University of Oxford, UK.

jane.kaye@law.ox.ac.uk 